Anuario Latinoamericano Ciencias Políticas y Relaciones Internacionales vol. 3, 2016 pp. 13-17

\section{América Latina: política y religión}

DOI: 10.17951/al.2016.3.13

\section{Latin America: politics and religion}

\section{Presentación}

\author{
Katarzyna Krzywicka \\ FACULTAD DE CIENCIAS POLÍTICAS \\ UNIVERSIDAD MARIA CURIE-SKŁODOWSKA \\ LUBLIN, POLONIA \\ katarzyna.krzywicka@umcs.edu.pl \\ Renata Siuda-Ambroziak, \\ CENTRO DE ESTUDIOS LATINOAMERICANOS \\ UNIVERSIDAD DE VARSOVIA, POLONIA \\ $\triangle$ r. siuda@uw.edu.pl
}

América Latina es actualmente una de las regiones más interesantes para las investigaciones del fenómeno de la religión, sus transformaciones contemporáneas y las relaciones dialécticas entre la religión y el mundo de la política. Estas dimensiones se entremezclan desde los tiempos coloniales, pero es ahora cuando se puede observar que la fuerza de la religión, en el contexto social y político del continente latinoamericano, está creciendo bruscamente. Aparecen nuevas iglesias y movimientos religiosos comprometidos políticamente, y la afiliación religiosa empieza a influir cada vez más, a la hora de las elecciones, en las decisiones de los latinoamericanos.

Las repúblicas latinoamericanas, que ya en los principios del siglo XIX parecían tender hacia el laicismo, secularismo y racionalidad, se dirigieron de nuevo hacia la religión. Este fenómeno despierta preguntas. ¿Es que la política en América Latina no puede prescindir de las referencias religiosas? ¿ $\mathrm{O}$ bien, es la religión la que se inclina excesivamente hacia la política, uniendo con eficacia lo divino con lo imperial? ¿Y si cualquier intento de separar decididamente la religión de la política tendría sentido y posibilidades de implementación, especialmente en una región de tan desarrollada religiosidad como lo es América Latina? Hay que destacar que la religión y la política en los países latinoamericanos raras veces funcionan por separado, aunque sí, acontece que están separadas forzosamente o bien, que son decididamente contradictorias. Estas dos dimensiones de la vida social crearon en América Latina una rela- 
Dossier América Latina: política y religión ción estable, aunque complicada, cuyos rasgos característicos a menudo son: la competencia y la hostilidad, pero también, muchas veces, la complementariedad y la cooperación en la realización de los objetivos comunes. Al parecer, en ningún otro lugar del mundo se puede ver con tanta evidencia que la complicada naturaleza humana es política y religiosa a la vez.

El dossier „América Latina: política y religión” se abre con un artículo de Armando Lampe, dedicado al conflicto entre el Vaticano durante el pontificado de Juan Pablo II y los representantes de la teología de liberación latinoamericana, en la persona de Ernesto Cardenal (el Ministro de Cultura en el gobierno revolucionario, sandinista de Nicaragua). Explicando la complejidad histórica e ideológica de este conflicto, que tuvo lugar en los años 80 del siglo XX, el autor recuerda los finales del siglo XIX y subraya la importancia de los cambios implementados en la diplomacia vaticana por el cardenal Rampolla, el Secretario de Estado de la Santa Sede durante el pontificado de León XIII, para la evolución del conflicto en Nicaragua y las maneras de solucionarlo. Al caracterizar la doctrina de Rampolla, Armando Lampe trata de responder a la pregunta si fue adecuada su aplicación por parte de Juan Pablo II, en el contexto muy específico socio-político-cultural de la revolución sandinista. Asimismo, al destacar las relaciones históricamente muy estrechas entre el mundo de la religión y de la política en Nicaragua, trata de comprobar la necesidad de la participación activa de la Iglesia católica en el derrocamiento de la dictadura sangrienta de Somoza, como también en el gobierno de Daniel Ortega.

En el siguiente artículo, los investigadores brasileños - Marcos Antonio da Silva y Lucimara Inácio do Prado da Silva, se ocupan también del tema de las relaciones entre religión y política en el contexto revolucionario, analizando la historia de los conflictos del gobierno de Fidel Castro en Cuba con la Iglesia católica. Los autores centran su atención en las disputas y mediaciones llevadas con el fin de establecer el diálogo y en los importantes cambios en las relaciones entre el Estado y la Iglesia en la isla, durante la Revolución Cubana. Observando la gran importancia de las relaciones religión-política en Cuba, subrayan que la falta total de entendimiento entre los representantes del gobierno y de la Iglesia en los años sesenta evolucionaba paso a paso hacia la suavización de las tensiones y el inicio de una cooperación limitada. Esta política empezó a dar frutos no antes de la caída del Bloque del Este. Los autores opinan que tanto la nueva situación geopolítica como el descenso brusco del nivel de vida de los cubanos, influyeron, de manera significativa, en el paulatino acercamiento de los líderes del partido y los jerarcas católicos, junto con los resultados positivos de la primera visita en la isla del papa Juan Pablo II.

Cuba es también el tema del tercer artículo, escrito por Beata Bereza, en el que la autora analiza la importancia de tres visitas papales a Cuba (de Juan Pablo II, Benedicto XVI y Francisco), como también la influencia del contenido de los discursos pronunciados por los soberanos de la Santa Sede en los cambios socio-políticos y en los cambios del carácter de las relaciones entre religión y política en Cuba. Presentando la realidad de la vida de los cubanos 
antes, durante y después de las visitas papales, la autora subraya, sobre todo, las dificultades en la formulación de una valoración claramente positiva de la primera visita, la del papa Juan Pablo II, que tuvo lugar durante el período de la crisis económica muy aguda en Cuba, y que no dio como resultado, en contradicción con las expectativas del papa-polaco y del mundo occidental, un cambio tan grande en las relaciones entre el Estado y la Iglesia y en la política interior cubana, como pasó durante su primera visita a Polonia. Beata Bereza enfatiza el carácter específico, por su marcado sincretismo, del catolicismo cubano y observa también que las religiones afro-cubanas fueron ignoradas durante las tres visitas, a pesar de su gran importancia para la religiosidad de los cubanos, también de los que oficialmente declaran su pertenencia a la Iglesia católica.

En el artículo siguiente, Magdalena Krysińska-Kałużna describe las relaciones entre religión y política en el contexto de las actividades de las misiones de las iglesias protestantes entre las tribus de los indios en la región de la Amazonia, y de los vínculos de esas instituciones religiosas con los intereses económicos y políticos de los países de origen de los misioneros, quienes se convertían, como en los casos citados por la autora, en los emisarios de dichos intereses. Los vínculos de las Iglesias Misioneras con la política, especialmente en el contexto de la guerra fría, así como el rol de la actividad de los misioneros procedentes de los Estados Unidos para la estrategia global de la expansión económica de las empresas norteamericanas, junto con la limitación de las influencias de la teología de la liberación católica y de las organizaciones de la izquierda, se convierten en una prueba más de los lazos existentes entre los elementos religiosos y políticos en el área de las relaciones socio-culturales en América Latina.

El artículo de Luís Fernando Pacheco Gutiérrez aborda la cuestión de la influencia de la religión sobre la dinámica de los movimientos socio-políticos en la región de América Latina, desde la segunda mitad del siglo XX. El autor analiza los casos de algunos países, es decir de Argentina, Perú, Salvador y Colombia. Constata que tanto las actividades de la Iglesia católica en ese período (independientemente de la estrategia adoptada por los jerarcas locales respecto a los sucesivos gobiernos) como el rol de la diplomacia del Vaticano para solucionar las crisis políticas y los conflictos internos tienen gran importancia en los procesos de cambios socio-políticos y económicos. A partir del momento cuando los países de la región fueron introducidos en el área de las actividades relacionadas con la guerra fría y desde la aparición de las dictaduras militares y los movimientos guerrilleros de la izquierda hasta los tiempos del inicio de las transformaciones multietapas de los sistemas políticos, relacionados con el regreso a la democracia y el ajuste de cuentas con las dictaduras derechistas por los delitos cometidos. La Iglesia católica y sus representantes en la región - conforme con la estrategia adoptada, que oscilaba entre la colaboración con los regímenes militares, los intentos de intervenciones, negociaciones y mediaciones entre el gobierno y la oposición y el conflicto - desempeñaron un

\section{Presentación}

Katarzyna Krzywicka Renata Siuda-Ambroziak 
Dossier América Latina: política y religión papel importante y muy activo en la formación de relaciones entre la religión y política.

Marta Wójtowicz-Wcisło, en el artículo dedicado a la problemática de la laicidad en la política interior de México, reflexiona sobre la diferencia en la posición de distintos actores del escenario político del país (incluida la Iglesia católica, siempre dominante en el panorama religioso mexicano), con respecto a los cambios en la constitución, implementados en el año 2010, que tienen por objetivo ampliar la garantía de la libertad religiosa de los ciudadanos y confirmar el carácter plenamente laico del Estado. La autora trata de convencernos que, a pesar de la introducción en la mitad del siglo XIX de la división formal entre el Estado y la Iglesia, la Guerra Cristera (1926-1929) llevó a un significativo fortalecimiento de la posición de la Iglesia católica en México, y el principio de la laicidad del Estado no fue observado en práctica, quedando esta ley en letra muerta.

El último artículo presentado en el Dossier fue escrito por Marta Osuchowska. La autora analiza las relaciones entre el Estado y la Iglesia en Colombia desde el punto de vista del derecho canónico e internacional, centrando su atención en el contenido de los acuerdos de concordato firmados con la Santa Sede. Fueron sometidas al análisis las cuestiones de las dudas legales que resultan de las diferencias en la interpretación de las regulaciones legales, las posibilidades de aplicación de las disposiciones de los acuerdos como una forma de garantizar los derechos únicamente de una opción religiosa (el catolicismo), o de las interpretaciones legales orientadas al aseguramiento de la libertad religiosa de todos los colombianos, independientemente de su confesión y su afiliación religiosa oficial.

Los autores de los artículos presentados en el Dossier formularon muchas preguntas importantes. Primero, ¿cómo se desarrollaban y cómo siguen desarrollándose las relaciones entre religión y política en América Latina? ¿Puede América Latina llegar a ser un área de investigación de las relaciones e influencias mutuas entre religión y política? ¿Cómo investigar estas relaciones cuando su elemento clave es un fenómeno que presenta grandes dificultades a la explicación científica? ¿Y cómo entender y describir las complejas relaciones entre religión y política en América Latina, recordando que en el caso de la religión no todos sus aspectos se prestan al análisis científico? Existen, pues, los límites del conocimiento científico de la religión, este fenómeno difícil para penetrar y abordar con la mente y que, a menudo, no puede ser expresado mediante cifras y estadísticas. Por eso, algunas preguntas de investigación dedicadas a la temática de la religión y política no pueden ser simples, ni abarcar un solo plano. Y es que, en el caso de la religión, lo invisible puede resultar de máxima importancia, traduciéndose en las decisiones subjetivas de los latinoamericanos, relacionadas con la elección de la afiliación religiosa o de la representación política.

Sobre estas cuestiones complicadas estamos reflexionando en el tercer volumen del "Anuario Latinoamericano", en el que presentamos a los lectores 
siete artículos científicos, donde los temas tratados por los autores son interesantes, importantes y bien preparados, convirtiendo así la revista en un espacio del intercambio del pensamiento libre y de la discusión académica, con el respeto a los argumentos de fondo y la ampliación de los límites del conocimiento de los asuntos y procesos que funcionan en la frontera de dos mundos, sólo aparentemente separados, el de la religión y el de la política.
Presentación

Katarzyna Krzywicka

Renata Siuda-Ambroziak 